\title{
Rhabdoid Tumor Predisposition Syndrome
}

National Cancer Institute

\section{Source}

National Cancer Institute. Rhabdoid Tumor Predisposition Syndrome. NCI Thesaurus.

Code C93268.

A neoplastic syndrome most often caused by mutations in the hSNF5/INI1 tumor suppressor gene. It is characterized by the development of an atypical teratoid/rhabdoid tumor in infancy and early childhood. This highly aggressive tumor develops in the central nervous system as an isolated lesion or in combination with extrarenal or renal rhabdoid tumor. Patients may also develop other central nervous system malignancies including medulloblastoma, supratentorial primitive neuroectodermal tumor, and choroid plexus carcinoma. 